\title{
Ruptured mediastinal pseudocyst with pancreaticopleural fistula formation in a 15-year-old boy presenting with white-out hemithorax: A case report
}

\author{
Mohd Monis $^{1}$, Md Khalaf Saba ${ }^{2}$, Syed M Danish Qaseem ${ }^{3}$, Nadeem Arshad ${ }^{1}$ \\ From ${ }^{1}$ Senior Resident, ${ }^{2}$ Junior Resident, ${ }^{3}$ Assistant Professor, Department of Radio Diagnosis, Jawaharlal Nehru Medical College, AMU, Aligarh, \\ Uttar Pradesh, India
}

\begin{abstract}
Pancreaticopleural fistula (PPF) is a rare complication of chronic pancreatitis described more commonly in adults with alcoholic and necrotizing pancreatitis. We report a rare case of ruptured mediastinal pseudocyst with the formation of PPF in a 15-year-old boy who presented with progressive dyspnea and large left-sided pleural effusion that recurred despite repeated drainage. On the basis of imaging findings and pleural fluid analysis, the diagnosis of PPF with ruptured mediastinal pseudocyst was made. The diagnosis of PPF should be considered in patients with non-resolving large left-sided pleural effusions. The diagnosis can be confirmed either by significantly raised amylase levels in pleural fluid or direct visualization of the fistula on Computed tomography/magnetic resonance cholangiopancreatography.
\end{abstract}

Key words: Pancreaticopleural fistula, Mediastinal pseudocyst, Chronic pancreatitis

$\mathrm{P}$ ancreaticopleural fistula (PPF) is a rare complication of chronic pancreatitis and a cause of significant morbidity and mortality. The entity has been described more commonly in adults with alcoholic and necrotizing pancreatitis. The presentation is often misleading because of the patients presenting with pulmonary symptoms such as dyspnea with a lack of signs pointing towards a pancreatic disease. Abdominal pain is a rarely reported symptom. Left-sided pleural effusions are seen more commonly and are usually large, and recur despite repeated drainage [1]. The diagnosis is often delayed and most of the patients have been usually subjected to extensive investigations to rule out a pulmonary cause before the diagnosis of PPF is made. Amylase-rich pleural fluid suggests the diagnosis.

We report a rare case of ruptured mediastinal pseudocyst with the formation of PPF in a 15-year-old boy who presented with white-out hemithorax.

\section{CASE REPORT}

A 15-year-old male presented to the emergency department with complaints of progressive breathlessness for 2 months.

On examination, the patient was tachypnoeic (respiratory rate of 20/min) along with tachycardia (pulse rate of 108/min).

\section{Access this article online}

Received - 01 November 2021

Initial Review - 17 November 2021

Accepted - 01 December 2021

DOI: $10.32677 /$ ijcr.v7i12.3207
The body temperature and blood pressure were normal. There was absent air entry with dullness on percussion on the left side on respiratory examination. Abdominal examination was unremarkable.

Routine blood investigations and chest radiographs were obtained. Biochemical parameters were as follows: $\mathrm{pO}_{2}-$ $76 \mathrm{mmHg}, \mathrm{pCO}_{2}-32 \mathrm{mmHg}, \mathrm{spO}_{2}-94$, albumin-3.5 gm/dl, total calcium- $8.5 \mathrm{mg} / \mathrm{dl}$,ionized calcium- $1.1 \mathrm{mmol} / \mathrm{L}$, and normal sodium, and potassium levels. Blood counts revealed mild leucocytosis. Liver and kidney functions tests were normal. The radiograph revealed complete white-out left hemithorax with features of contralateral mediastinal shift (Fig. 1).

The diagnosis of massive left-sided pleural effusion was made and the chest tube was inserted. Pleural fluid samples were analyzed and revealed an exudative pattern with normal adenosine deaminase levels. However, the effusion was found to recur despite repeated drainage procedures.

Contrast-enhanced computed tomography scan of the patient was performed. Two well-defined cystic lesions showing thin peripheral enhancement were seen in the mediastinum on either side, along with bilateral pleural effusions (predominantly on the left side). Furthermore, there was indistinct visualization and non-enhancement of cyst wall along the posterolateral aspect of the left-sided mediastinal cyst suggesting rupture into the pleural space. These mediastinal cysts were also found to be communicating with

Correspondence to: Dr. Mohd Monis, Senior Resident, Department of Radio Diagnosis, Jawaharlal Nehru Medical College and Hospital, Aligarh, Uttar Pradesh, India. E-mail: mmonis44@gmail.com

(C) 2021 Creative Commons Attribution-NonCommercial 4.0 International License (CC BY-NC-ND 4.0). 
the abdominal cavity through aortic hiatus. Upper abdominal sections revealed atrophic pancreas, pancreatic duct dilatation, intraductal calcifications, and cystic lesion of similar characteristics as a mediastinal cyst in the splenorenal region. This splenorenal cyst had a communication with the main pancreatic duct. These imaging features suggested chronic pancreatitis with pseudocyst formation (Fig. 2). Pleural fluid samples were sent for amylase levels. Biochemical analysis revealed markedly raised amylase levels ( $>5000$ units) in the pleural fluid. The diagnosis of ruptured mediastinal pseudocyst with PPF formation was made. The patient was referred to the higher center for further management where lateral pancreaticojejunostomy was performed.

\section{DISCUSSION}

PPF is a rare complication of acute or chronic pancreatitis. It usually develops secondarily to leak from an incompletely formed or ruptured pseudocyst and rarely due to direct leak from the pancreatic duct. The fistulous communication is via aortic or oesophageal hiatus or sometimes directly transdiaphragmatically. Besides PPF, other types of thoracopancreatic fistulas have been described

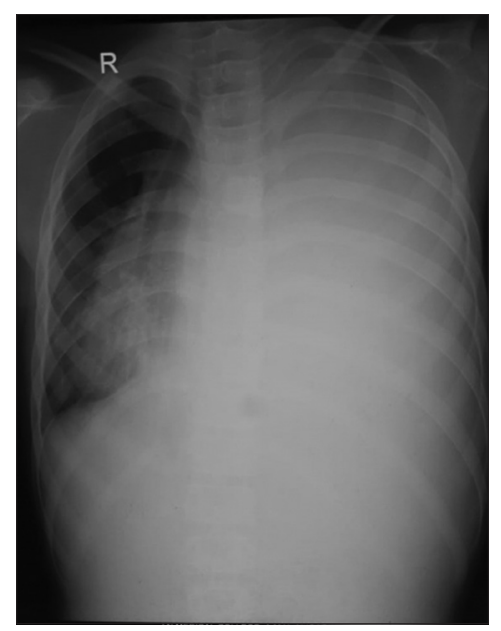

Figure 1: Chest radiograph of the patient shows complete white out left hemithorax with contralateral shift of mediastinal structures based on the site of termination of the fistula namely mediastinal pseudocyst, pancreaticobronchial, and pancreaticopericardial [2]. Inflammatory changes in the peripancreatic spaces allow the formation of these thoracopancreatic fistulas [3]. The mediastinal pseudocyst is usually located in the posterior mediastinum.

Most patients are adult males with a history of alcoholism with a reported incidence of approximately $0.4 \%$ in patients with chronic pancreatitis $[4,5]$. Patients typically present with respiratory symptoms with dyspnea being the most common presentation. Abdominal symptoms typical of pancreatitis are less common and most of the patients have gone through extensive investigations to rule out a pulmonary cause before the diagnosis of PPF is made.

Left-sided pleural effusions are common and are usually large, recurrent, and exudative in nature. It should be distinguished from the small reactive effusions commonly seen in patients with pancreatitis [6]. Pancreatic pseudocysts are noted commonly in patients who develop PPF.

The diagnosis of PPF is based on the detection of elevated pleural fluid amylase levels or direct demonstration of a fistulous tract on computed tomography (CT) or Magnetic resonance cholangiopancreatography (MRCP). CT is excellent in the evaluation of pleural effusions, defining pancreatic abnormalities, and depictions of pseudocysts. However, accurate delineation of the fistulous tract may not be possible with CT. MRCP is reported to be particularly useful in demonstrating the fistula tract [2]. MRCP offers advantage over Endoscopic retrograde cholangiopancreatography (ERCP) due to its non-invasive nature, depiction of parenchymal as well as extra parenchymal abnormalities [7].

Treatment approaches include both conservative and surgical options. Conservative management involves pleural fluid drainage, octreotide, fasting, and parenteral nutrition [8]. ERCP-guided stent placement is another non-surgical option in these patients [9]. Indications for surgical intervention include failure of conservative and endoscopic management. Surgical management may involve pancreatic resection or the creation of enteropancreatic anastomosis to the site of pancreatic duct leakage or to the pseudocyst.

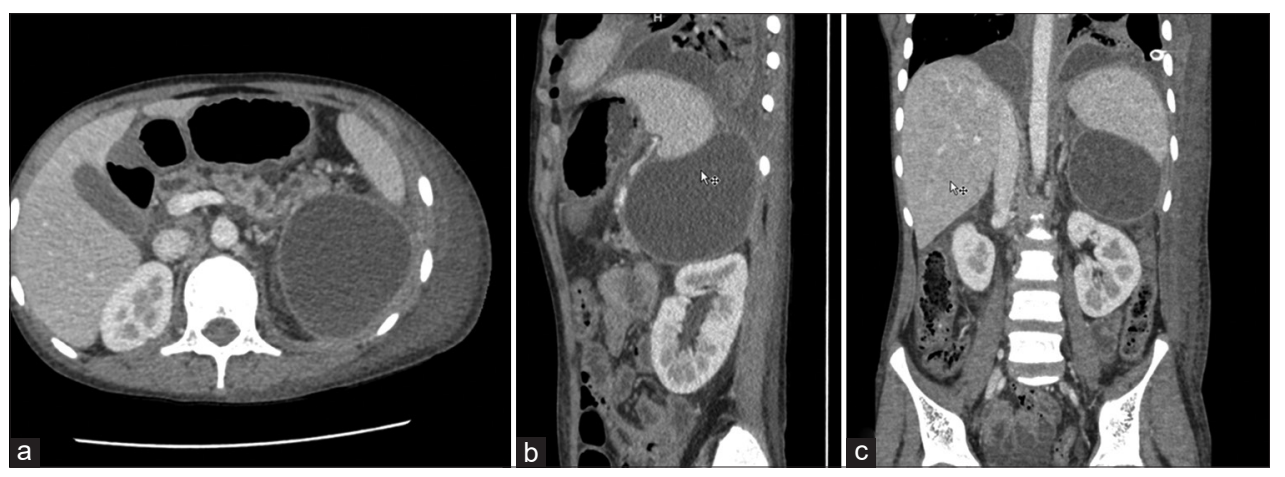

Figure 2: (a) Upper abdominal Contrast-enhanced computed tomography (CECT) sections of the patient shows a well-defined peripherally enhancing cystic lesion (pseudocyst) in splenorenal area. Also noted dilated main pancreatic duct; (b) Sagittal CECT sections of the patient shows indistinct visualisation and non-enhancement of the posterior wall of the mediastinal pseudocyst suggesting rupture into pleural cavity; (c) Coronal CECT sections of the patient shows bilateral mediastinal pseudocysts with apex directed towards aortic hiatus. Also noted a large pseudocyst in splenorenal area 


\section{CONCLUSION}

The diagnosis of PPF should be considered in patients with nonresolving large left-sided pleural effusions. The diagnosis can be confirmed either by significantly raised amylase levels in pleural fluid or direct visualization of the fistula on CT/MRCP. A review of upper abdominal CT sections may be helpful. Conservative, endoscopic, and surgical options are considered in the management of PPF.

\section{REFERENCES}

1. King JC, Reber HA, Shiraga S, Hines OJ. Pancreatic-pleural fistula is best managed by early operative intervention. Surgery 2010;147:154-9.

2. Vyas S, Gogoi D, Sinha SK, Singh P, Yadav TD, Khandelwal N. Pancreaticopleural fistula: An unusual complication of pancreatitis diagnosed with magnetic resonance cholangiopancreatography. J Pancreas 2009;10:671-3.

3. $\mathrm{Xu} \mathrm{H}$, Zhang $\mathrm{X}$, Christe A, Ebner L, Zhang S, Luo Z, et al. Anatomic pathways of peripancreatic fluid draining to mediastinum in recurrent acute pancreatitis: Visible human project and CT study. PLoS One 2013;8:0062025.
4. Ali T, Srinivasan N, Le V, Chimpiri AR, Tierney WM. Pancreaticopleural fistula. Pancreas 2009;38:26-31.

5. Aswani Y, Hira P. Pancreaticopleural fistula: A review. J Pancreas 2015;16:90-4.

6. Sut M, Gray R, Ramachandran M, Diamond T. Pancreaticopleural fistula: A rare complication of ERCP-induced pancreatitis. Ulster Med J 2009;78:185-6.

7. Materne R, Vranckx P, Pauls C, Coche EE, Deprez P, Van Beers BE. Pancreaticopleural fistula: Diagnosis with magnetic resonance pancreatography. Chest 2000;117:912-4.

8. Wronski M, Slodkowski M, Cebulski W, Moronczyk D, Krasnodebski IW. Optimizing management of pancreaticopleural fistulas. World J Gastroenterol 2011;17:4696-703.

9. Neher JR, Brady PG, Pinkas H, Ramos M. Pancreaticopleural fistula in chronic pancreatitis: Resolution with endoscopic therapy. Gastrointest Endosc 2000;52:416-8.

Funding: None; Conflicts of Interest: None Stated.

How to cite this article: Monis M, Saba MK, Qaseem SM, Arshad N. Ruptured mediastinal pseudocyst with pancreaticopleural fistula formation in a 15-year-old boy presenting with white-out hemithorax: A case report. Indian J Case Reports. 2021;7(12):547-549. 